\title{
Sociology, Science and Sustainability: Developing Relationships in Scotland
}

\author{
by Kirsty L. Blackstock, Elizabeth A. Kirk and Alison D. Reeves \\ Socio-Economics Research Programme, Macaulay Institute; Department of Law, University of \\ Dundee; Department of Geography, University of Dundee
}

Sociological Research Online, Volume 10, Issue 2,

< http://uww. socresonline.org.uk/10/2/blackstock.html>

doi:10.5153/sro. 1097

Received: 13 Oct 2004 Accepted: 20 Jun 2005 Published: 30 Jun 2005

\begin{abstract}
This paper considers the application of the sociological imagination during the analysis of data collected during an ethnographic study of an environmental regulator, the Scottish Environment Protection Agency (SEPA). SEPA is tasked with implementing the European Water Framework Directive (WFD) in Scotland, which will radically alter the regulation of water use. Applying a sociological imagination allowed the researcher to advocate for a more interdisciplinary and equitable understanding of sustainable water use when feeding back initial research results at the end of the data collection period. The researchers introduced socialised definitions of the environment, which linked social justice and ecological concerns. These insights provided a challenge to the traditional bio-physical science focus of the organisational participants, for whom sustainability is a relatively new addition to their duties. The paper concludes by discussing the importance of developing these interdisciplinary relationships in the future.
\end{abstract}

\section{Keywords: Sociological Imagination, Water Framework Directive, Sustainability Science, Consumer-Citizens}

\section{Introduction}

1.1 O'Riordan and Voisey (1998) illustrate how many post-fordist societies are undergoing a 'sustainability transition', which involves a dramatic shift from current society's resource use to a society that is premised on achieving sustainable development (defined below).

1.2 This shift is influencing regulation of the environment, involving a move away from the 'command and control' approach (prescribing standards, which trigger legal and financial penalties if breached) towards an approach that uses a combination of education, incentives and self regulation to encourage environmentally sustainable resource use, backed up by legal sanctions where required (Warren, 2002; Kramer, 2000). An important aspect of this process is the involvement of stakeholders and consumer-citizens (defined below) in environmental regulation (Fischer, 2000).

1.3 Social science perspectives, such as sociology, are central to facilitating this shift in environmental regulation, particularly as the collaborative approach described above requires increasing attention to the social, political and economic contexts in which environmental regulation takes place (Ross, 2000). The need for this interdisciplinarity in order to achieve more sustainable regulatory approaches prompted our research project, Disciplinary Interactions: Science and the Law ${ }^{[1]}$, which considered the relationships between individual officers' disciplinary perspectives, institutional culture and policy implementation, with particular reference to the European Water Framework Directive (WFD) and the mitigation of diffuse pollution. Our project found barriers to the implementation of a holistic approach to sustainable water use within SEPA and discusses the benefits of, and constraints to, developing such interdisciplinary relationships (see Kirk et al., forthcoming, Reeves et al., forthcoming).

1.4 This paper focuses on the way in which we were able to contribute to future regulation making within SEPA through constructive criticism of their processes, delivered largely at the end of our data collection processes. The paper illustrates how applying the sociological imagination was used to encourage an environmental regulator to develop a more equitable and interdisciplinary understanding of sustainable water use. Thinking sociologically entails considering the social forces that shape current societies, why the current arrangements came into being, and how individuals both shape, and are shaped by, these arrangements (Bauman, 1990). The sociological imagination (Mills, 1959) entails a critical analysis of the 
connections between individual circumstances (private troubles) and social forces (public issues), in order to deconstruct common sense assumptions about the way things are, and to ask how they could be otherwise. Whilst we recognise that sociology is not the only discipline that can contribute alternative perspectives on environmental regulation, this paper draws on the reflections of our field researcher, a sociologist, who carried out ethnographic work within the Scottish Environment Protection Agency (SEPA). The outcome of these reflections suggests that sociologists should work with environmental scientists in the quest for sustainability.

1.5 Our paper concentrates on illustrating how the sociological imagination was used to introduce alternative ways to conceptualise water use and therefore implement the WFD. The WFD requires a fundamental shift in the regulation of the water environment in a number of ways, including an explicit requirement for collaborative decision making and 'the active involvement of interested parties' (Council of European Union, 2000). However, our ethnographic work indicates that SEPA consistently prioritised scientific issues of water quality over social and economic factors influencing the sustainable use of water in Scotland. Furthermore, their narrow and instrumental interpretation of 'stakeholders' was likely to exclude direct participation in the WFD by individual citizens ${ }^{[2]}$. Our researcher's sociological imagination allowed her to challenge these perspectives and introduce SEPA staff to alternative ways to conceptualise water use and water users.

1.6 The paper begins by introducing our main theoretical ideas about sustainability science (Kates et al., 2001) and citizen involvement in environmental regulation. We consider the arguments for an interdisciplinary approach to water use and why these interdisciplinary approaches may be resisted. We then provide contextual information about the host organisation and the Water Framework Directive, which is the legislative driver for the shift to sustainable water use within the host organisation. The study methodology is explained, including the way in which the researcher's sociological imagination was stimulated during our 'Disciplinary Interactions' project. We focus on the ways in which the sociological imagination was used to argue for a broader understanding of sustainable water use via three case studies, the WFD characterisation process, a discussion paper on social uses of water and the definition of stakeholders within SEPA. These reflections were shared towards the end of the data collection period to avoid unduly influencing the processes we sought to observe. We end the paper with a discussion regarding the reception our arguments received and our reflections on our experiences.

\section{Conceptual Foundations}

2.1 The relationship between sociology, science and sustainability is important for two reasons. Sustainability requires a holistic, interdisciplinary understanding of the resource. Sociologists are well placed to provide the 'social' element of interdisciplinary work, using conceptual tools to think about the social, cultural and economic context of sustainable water use and critically considering the relationship between social structures and social actors, the historical precedents for these relationships and possibilities for change. Sustainability also requires the engagement of active citizens and sociologists are well placed to facilitate this. These twin conceptual foundations, underpinning our argument to improve relationships between sociology, science and sustainability, are briefly examined in turn, followed by a review of potential barriers to interdisciplinary relationships.

2.2 Sustainability science (Kates et al., 2001) requires an interdisciplinary understanding of socioecological systems. Sustainable development can be defined as 'development that meets the needs of the present without compromising the ability of future generations to meet their own needs ${ }^{[3] '}$ (WCED, 1987). Sustainability focuses on the positive interconnection between a healthy economy, vibrant communities and a thriving bio-physical environment, coupled with attention to intra- and inter-generational equity ${ }^{[4]}$. Achieving sustainability requires adaptive management approaches (Walker et al., 2004) that conceptualise the environment as a complex, non-linear and dynamic system. This system consists of ecological and biophysical processes and the human actors that are shaped by and shape their environment. Therefore, sustainability science requires an understanding of all the components of these systems and their interactions.

2.3 Developing sustainable approaches to environmental problems in our risk society (Beck, 1992) has to consider change, complexity, uncertainty and conflict due to imperfect scientific knowledge and the indeterminacy of complex processes (after Van den Hove, 2000; Kates et al, 2001). This context unsettles the past relationship between science and policy, whereby citizens deferred to the scientists' cognitive authority, gained through scientific credentials (Barnes and Edge, 1982; Fischer, 2000). These scientific experts responded to scientific problems on behalf of citizens, making informed judgments and providing technical guidance to elected representatives, who then act. However, in the context of uncertainty, 'typically, we find the ... framing of the problem involves politics and values as much as science' (Ravetz, 1990 quoted in Newby, 1997: 475), and requires new forms of deliberative democracy (O'Neill, 2001). 
2.4 Thus, citizens no longer trust the state to develop the appropriate institutional response to environmental problems but demand an active role in defining and implementing solutions in partnership with government and regulators (Goldblatt, 1999; Smith, 1998, Fischer, 2000; OECD, 2001). These partnerships have substantive, instrumental and normative benefits for environmental regulation (Stirling, forthcoming; Pellizzoni, 2003). The first, substantive, reason for active involvement is to improve problem scoping and solution identification by ensuring that multiple perspectives and forms of knowledge are considered when defining the problem. This will assist decision-makers as regulatory issues are rarely entirely bio-physical, or solutions purely technological (Beirle and Konisky, 2001). The second, instrumental, reason arises because attempts to resolve problems by implementing a decision or a policy will be more effective if a broad coalition supports the plan and works together to deliver it. Furthermore, a transparent process in which conflicting claims and views are considered can increase public trust in the final outcome, and therefore public acceptance of policy implementation and its associated public expenditure (OECD, 2001). The third, normative, reason for stakeholder involvement illustrates that this not only enhances the effective implementation of the plan but also has broader implications for building an active civil society. Engaging in processes that meet the criteria of equity; fairness; competency; freedom and legitimacy (Webler et al., 2001) enriches both individual participants and society, as they enable participants to become active and engaged citizens in a deliberative democracy.

2.5 This paper therefore conceptualises citizens as social actors engaged in civil society, who are active players in the 'sustainability transition'. As outlined above, involving citizens in environmental regulation should result in environmentally rational and socially just outcomes, in turn contributing to continued social solidarity (Baber, 2004). Citizens are also consumers, and the processes of consumption play a fundamental aspect in identity creation and definition in our post-fordist society (Giddens, 1991). Consumption also raises issues about distribution and social justice, particularly with regard to access to resources. Therefore the sustainable use of water is an intensely political issue, requiring an engagement with sociological issues of scarcity and solidarity (Turner and Rojek, 2001). This paper views the consumer as a politicized social actor who is able to think through the consequences of their consumer choices (O'Connor and Wynne, 1996), hence the use of the term consumer-citizen (Slocum, 2004).

2.6 The consumer-citizen is an embodied actor (Turner and Rojek, 2001) who is both responsible for, and vulnerable to, environmental change. Therefore the sociological imagination suggests that the sustainable use of water must be thought about in terms of environmental justice - 'the fair treatment and meaningful involvement of all people regardless of race, colour, national origin, or income with respect to the development, implementation, and enforcement of environmental laws, regulations, and policies' (EPA, 2003). Environmental justice draws our attention to the fact that the most powerless in societies tend to be those who are disproportionately affected by environmental degradation but are least able to pay for improvements (Hamilton, 1996).

2.7 These preceding arguments illustrate why sustainable water use requires a broader perspective, including an understanding of the socio-political context, than the traditional focus of the bio-physical sciences on metrics of water quality and quantity (Warren, 2002; Newson, 1996). These ideas draw on Thomas Kuhn's notion of paradigmatic revolutions (Barnes and Edge, 1981), which highlights the politically and socially constructed nature of science. The failure of traditional science to resolve environmental problems has been linked to the reductionism inherent in specialized scientific professions (Lubchenco, 2001; Pawson and Tilley, 1997). In contrast, sustainability science requires scientists to critically engage with multiple forms of knowledge (Kates et al, 2001). However, our study 'Disciplinary Interactions', illustrated the imbalance in perspectives framing environmental regulation (Kirk et al., 2004; Sherlock et al., 2004; Kirk et al, forthcoming, Reeves et al., forthcoming).

2.8 However, social scientists are also guilty of side stepping the challenge of interdisciplinary work on the environment. Murphy (2002) criticizes contemporary sociological writing for ignoring the urgency of the global environmental crisis. This occurs as nature as an autonomous subject is abolished or bracketed out in sociological writing, denying the material reality of the environment. Newby (1997) links this to the traditional demarcation of the social from the biological. In our view, sustainable water use requires interdisciplinary collaboration to overcome this false binary opposition between society and nature. It was the observation that social scientists often retreat from the challenge of interdisciplinary research that prompted our reflection on the sociological imagination whilst analyzing the data generated by our research project.

2.9 However, interdisciplinarity continues to be an elusive goal (see Tress et al., 2005). This has been explained with reference to disciplinary commitments and to path dependency (Kirk and Reeves, 2002; Kirk et al., forthcoming, Reeves et al., forthcoming). Disciplinary commitments predispose scientists to particular ways of seeing the world (Landesmann, 1997; Jasanoff, 1999) and in particular, environmental regulators continue to work within a positivist paradigm, which privileges technical and scientific solutions 
(Wakeford and Walters, 1995). This is perpetuated because specialist scientific knowledge is accumulated through shared practices and language (Barnes and Edge, 1981) and specialized disciplinary commitments are maintained through exclusionary discourses (Foucault, 1991; Pawson and Tilly, 1997). The notion of path dependency (Arthur, 1985) highlights the practical and financial constraints on considering alternative courses of action once a particular process becomes established. Thus, the transaction costs of moving from existing disciplinary commitments to a more holistic approach like sustainability science can be offputting. These theories help to illuminate the barriers to interdisciplinary approaches to environmental regulation, in turn highlighting what issues need to be addressed to achieve a more sustainable approach to water use regulation.

\section{Context}

3.1 Hassard and Kelemen (2002) suggest that scientific knowledge must be considered within the material, institutional, political and cultural context in which it is produced (see also Wakeford and Walters, 1995). This paper draws on fieldwork undertaken at SEPA, which is responsible to the Scottish Parliament through the sponsor department of the Scottish Executive. Because SEPA is a non-departmental public body, it plays a mediating role between the State and civil society. Thus our research participants act within a political policy arena, although their organisational culture perpetuates the myth of a value-free, neutral bureaucracy.

3.2 SEPA is one of the competent authorities implementing the WFD (2000/60/EC). The WFD is profoundly influenced by sustainability as its objective is to establish sustainable water use in the European Community (Scottish Executive, 2002a). Water is central to sustainable development, as illustrated through the 'Dublin Statement' issued at the International Conference on Water and Environment in 1991. This statement, which underpinned the development of the WFD (Kramer, 2000), highlighted the need for the sustainable use of this finite resource and for participatory approaches to achieve this sustainable use (Owen and Unwin, 1997).

3.3 These arguments have triggered a shift from a narrow, chemically orientated focus on point source pollution of water to a broader, holistic perspective on water use and its implication for water quality (Edwards, 1997). The WFD requires a move away from regulating for 'end of pipe' solutions, which capture and process pollutants, to a proactive approach to minimize pollution occurring at all, which is particularly important given the increasing threat posed by diffuse pollution (see Reeves et al., forthcoming). This shift is to be achieved through River Basin Management Plans (RBMP), as shown in Figure 1 below. The directive has been described as 'the most significant change in environmental legislation covering the aquatic environment in thirty years' (Scottish Executive, 2001). In fact, the Water Environment and Water Services (Scotland) Act 2003 is the first time that comprehensive water management planning has been implemented in Scotland (Scottish Executive, 2002).

3.4 The development of a RBMP for Scotland is a radical change for environmental regulators. It requires an interdisciplinary engagement with causes and consequences of catchment degradation (Warren, 2002). In turn, this requires a socio-economic understanding of the river basin context and the various users of the resource. The directive also specifies the participation of local stakeholders in defining the environmental objectives and programme of measures that make up the RBMP. We believe that the twin conceptual foundations of sustainability science and participation by consumer-citizens are pre-requisites for implementing the WFD in Scotland.

\section{Methodology}

4.1 The ethnographic fieldwork took place in an environmental regulatory organisation, SEPA, from April to December 2002. Our research followed the qualitative organisational studies tradition (Miller, 1997), applying it in an environmental rather than social policy context. The analysis is influenced by the tensions inherent in ethnographic work, between emersion in the organisational culture to provide a credible and authentic account whilst maintaining enough critical distance to avoid 'going native' (Harrington, 2002). Our researcher's different disciplinary background allowed her to use the technique of the naïve ethnographer (Shaffir and Stebbins, 1991), to question taken for granted institutional processes. 


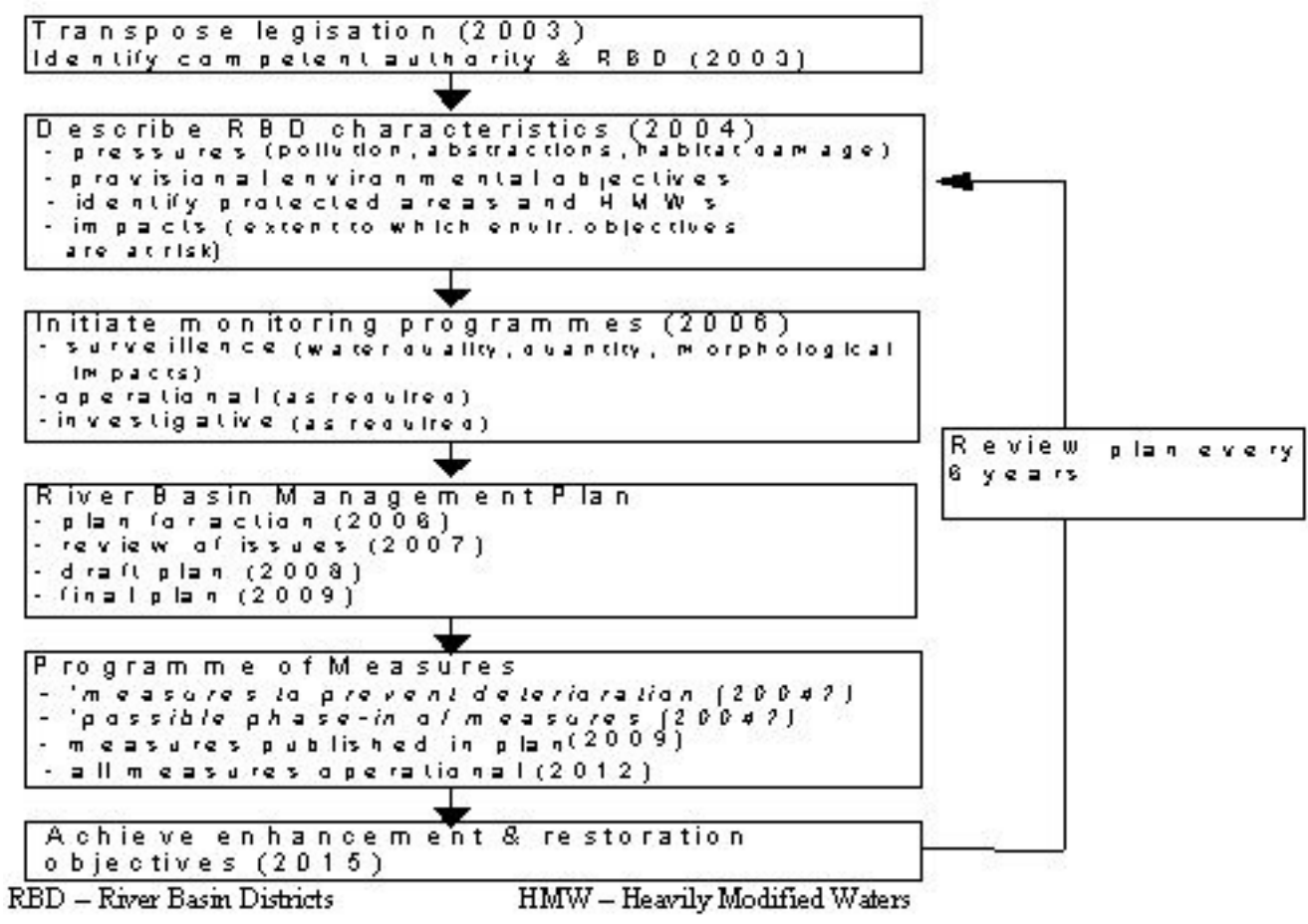

Figure 1. Overview of Directive requirements

Source: SEPA (2002)

4.2 Our project sought to establish the role of disciplinary interactions on the development of environmental regulations. Our particular interest was in diffuse pollution, given that this is predicted to become the main cause of environmental downgrading of Scottish waterways during the next decade (Scottish Executive, 2001). Our remit included the implementation of the WFD in Scotland, as this will be the main tool for tackling diffuse pollution. The focus on sustainability in the WFD provided a nice contrast to the existing approaches to diffuse pollution in Scotland and linked with our ideas about interdisciplinary working for sustainable outcomes (see Reeves et al., forthcoming).

4.3 Our data collection methods included participant observation of meetings $(\mathrm{N}=39)$ and day to day practices in the office, plus in-depth interviews $(N=16)$. Many participants' voices $(N=102)$ inform our analysis, including the 'real time' voices recorded in meeting transcripts, the 'reflective' voices of our interviewees and the impressions of our field researcher through her field notes. Our sample was selfselecting in that we were observing pre-existing practices and meetings. Of the sample, 73 were employees and 29 were from other organizations (academics; civil servants; industry representatives and NGO representatives). The sample consisted of 24 women and 78 men and their average age was 30 - 39 years. The participants were generally highly qualified, for example, 17 had PhD's and 24 had MSc's. The majority had bio-physical science ${ }^{[5]}$ qualifications $(N=49)$, five had arts or social science qualifications and the remaining participants did not specify the subjects in which they were qualified.

4.4 Our qualitative data analysis sought to demonstrate where observed practices corresponded to or deviated from our theoretical assumptions, including an analysis of silences in the transcripts. The approach could be characterized as abductive (Chalmers, 1982) as we began with broad research questions but included issues arising from the data in their analysis. This allowed us to include the participants' construction(s) of social reality (Silverman, 2000). We worked from a critical realist perspective, considering data as evidence of actions whilst using field diaries to reflect on the contingent nature of this evidence. Whilst the majority of the analysis was focused on responding to our overall research questions, the analysis for this paper concentrates on exploring how the field researcher's own discipline, and therefore her sociological imagination, informed the way that SEPA sought to think about regulating sustainable water use.

4.5 The research design emphasised a relatively passive research presence to preserve the naturalistic interactions during the meetings and our field researcher's sociological background was not a intrinsic part of the research design. As our researcher was negotiating entrance to the field, we had to manage the host organisations' emphasis on reciprocity. It emerged that our researcher's professional training was of particular interest in this regard. As one participant put it, 'I think the important aspect is that it should provide us with something we haven't got. And we haven't got the sort of experience that you've got. Now there might be some benefit in terms of just coming into it from a different perspective and seeing what we do from another perspective but I suspect the main value will be in terms of your own professional 
experience' (Meeting, April, 2002). Ironically, SEPA were asking our researcher to become involved in developing an interdisciplinary approach to sustainable water use, whilst researching disciplinary commitments.

4.6 The interest in our researcher's sociological background stemmed from the host organisation's extended responsibilities under the new WFD regime, as assessing social and economic outcomes requires new skills and approaches. The need for a social science perspective was pressing, as participants confided that 'we need pointing in the right direction, we have no idea what the social use of water even means ' (field notes, April). Another stated 'they are things that we just haven't ever had to think about...there's certain kind of paradigms we understand very well in this sort of implementation, and there [are] other things that we are kind of baffled by' (interview, April).

4.7 The role our researcher could play in meeting their self-confessed skill deficit was raised during eight field noted discussions, in six introductory interviews and during two official meetings. For example the annotations on the transcript of our first meeting state: 'key moment for me as second time I have been asked today. With the context of lack of time, lack of resource, references to burn out and stress it seems clear I could not just say 'observer' and get cooperation from them'. Thus we had to negotiate a process of constructive engagement, whilst remaining methodologically aware of the issues that this process might create (Harrington, 2002). We reached a compromise whereby we sought to protect our position of passive observation during the data collection period, and in return, would respond to these requests towards the end of the research, as part of the broader process of feeding back our research findings. Through sharing our conference paper on the WFD characterisation process, our working paper on the social use of water, and verbal feedback on stakeholder definition and engagement at the end of 2002, we were able to answer their requests, whilst retaining the overall focus on our Disciplinary Interactions project during the data collection period.

\section{Discussion}

5.1 As discussed above, our researcher's sociological imagination became a resource for participants and our discussion focuses on how this sociological imagination informed the way that SEPA might think about regulating sustainable water use in the future. Thinking sociologically broadened the participants' understandings of sustainable water use and challenged the dominant value free and positivistic approaches within the host organisation. The benefits of developing this interdisciplinary relationship can be illustrated through examples drawn from our fieldwork. Firstly, our researcher provided a commentary on the development of the characterisation report, where she highlighted the importance of a holistic approach to measuring pressures and impacts on the aquatic environment. Secondly, the researcher was requested to develop a briefing paper on the social uses of water, in which she drew attention to the symbolic as well as material consumption of water, and the intra- and inter-generational equity issues associated with water use. Thirdly, she provided a critique of stakeholder involvement, where she explained how SEPA's definition of stakeholders, and their instrumental rationale for involving these in implementing WFD, could exclude individual consumer-citizens with corresponding implications for civil society and environmental regulation.

\section{Example One: WFD Characterisation Report}

5.2 The characterisation report is the foundation stone upon which the RBMP will be built (see figure one). It is the first stage in implementing the WFD and requires the identification of all water bodies in Scotland, an analysis of their current ecological status and a prediction of their status in 2015 as WFD requires all water bodies to achieve good ecological status. SEPA have adopted the DPSIR (driving forces, pressures, state, impact and response) methodology for characterisation. Adopting the DPSIR approach reinforces the philosophy of taking a holistic approach to characterising the water environment, as the DPSIR approach links environmental impacts to their social pressures (Rekolainen et al., 2004; Vicory et al, 2002; Becker and Fehr, 2002).

5.3 However, during WFD meetings, it became clear that the emphasis continued to be on the ecological states and impacts, rather than the anthropogenic driving forces that created the pressures on the aquatic environment. The disciplinary bias can be illustrated by the occasion where officers prioritised natural science projects over economic projects in a characterisation budget meeting, therefore denying these projects a budget (meetings April and May, 2002). At these meetings, the relatively strong influence of natural scientists (ecologists and hydrologists) overwhelmed the lone voice of the organisation's economist, and there were no other participants representing social science perspectives involved in the characterisation process. As one participant ${ }^{[6]}$ commented 'the prioritisation of the work is sometimes also driven by vested interests within SEPA. For example the science functions are large and well organized and so get the lion's share of resources' (interview, October, 2002). 
5.4 This imbalance between natural and social sciences jeopardizes the foundation for sustainable water use in Scotland. Given that the causes and consequences of environmental problems are social issues (Giddens, 2001), attempts to predict future ecological status will falter without an understanding of the socio-economic pressures on water bodies. The Scottish aquatic environment is only 'semi-natural' due to the modification to flows through irrigation, impoundment, flood controls and land reclamation (Warren, 2002). Thus, the ecology of water bodies in Scotland has to be considered as part of a socially mediated landscape (Smith, 1999a). Attempts to model bio-physical states and impacts without understanding the origins of their pressures can only give a false picture. In the words of Linehau and Gross 'the problem with quantitative ecology is simply that the sheer complexity of the world, society and issues renders even the most complex and incomprehensible set of equations grossly simplistic' (1998:210).

5.5 However, the imbalance was not fully appreciated by the group until it was presented to them in the form of a conference paper developed by our research team (Sherlock et al, 2002) as part of the 'exiting the field' process. This paper highlighted how disciplinary commitments perpetuated the focus on ecological states and impacts and ignored the broader driving forces. We highlighted the dangers of taking a purely technical approach to predicting ecological status and explained the importance of understanding the socio-political driving forces on Scotland's aquatic environment. Thus, the sociological imagination helped illustrate these participants' taken for granted assumptions and disciplinary biases underpinning their initial approach to characterisation. This awareness should lead to a more holistic characterisation approach and therefore strengthen the foundation for WFD implementation in Scotland.

\section{Example two: Social Uses of Water}

5.6 The sociological imagination was actively engaged in providing recommendations to assist the host organisation incorporate their new duties under the WFD. As an excerpt from our researcher's June field notes illustrates, the host organisation wanted assistance understanding the social uses of water. ' 3 wants guidance on the process, particularly on the social. How do we do it? Where do we start? Requested a 3 4 page briefing. Explained that they don't know what the social is. They need something to get a handle on it and how to talk to people about it.' In response, we developed a paper highlighting our understandings of the social uses of water and how the host organisation might address the issues raised, which was presented in December 2002. This paper illustrated how the discipline of sociology could broaden the host organisation's understanding of sustainable use of water, illustrating how developing relationships between disciplines can help develop sustainable outcomes.

5.7 We argued that the host organisation had to focus on consumption of water rather than pollution resulting from production processes. As 'sociology is a science that begins with the social relationships of everyday life and the conditions that shape it' (Turner and Rojek, 2001:viii), we drew attention to the everyday consumption of water. Thus sustainable water use is not only about industrial processes but also about the role that water plays in bodily processes, for washing, drinking, cooking and cleaning. Although the host organisation does not have responsibility for regulating these activities, its role as lead authority for RBMP requires it to engage with this issue. In particular, thinking about sustainable use means engaging with consumer-citizens to encourage more responsible consumption of the resource.

5.8 Throughout the paper, we used our sociological imagination to illustrate how sustainable water use requires a broad understanding of the symbolic as well as material uses of water. The consumption of the aquatic environment extends beyond the literal use of water to drink to the consumption of aquatic landscape for recreation and amenity. We introduced participants to a socially constructed reading of the environment, arguing that as social beings, we inscribe symbolic meaning onto our physical surroundings (Aitchison, Macleod and Shaw, 2000). Thus, water bodies play a role in maintaining a sense of place and place is invested with social meanings and identity (O'Connor, 2000). This is a very different approach to the way that water courses were constituted in the discourses of our host organisation, whereby rivers, lochs and transitional waters were seen as objects for protection, as revealed by the reference to technical definitions of 'water bodies' during WFD meetings. Thus, sociologists can help environmental regulators see the aquatic environment as a subject constituted through everyday acts of symbolic consumption (Shrive, 1994).

5.9 The water environment has a symbolic role in developing and negotiating identity on individual, local, regional and national level. The first article of the WFD stresses water as heritage, highlighting its function as a symbolic resource. The National Cultural Strategy for Scotland (Scottish Executive, 2000) identifies access to natural heritage as integral to Scotland's culture. In Scotland, the aquatic environment is not only part of a very successful brand (McCrone et al, 1998) but is also part of mythological and literary heritage (Aitchison, MacLeod and Shaw, 2000). Equally, landscape can be linked to processes of national identity (Hobsbawn and Ranger, 1987; Mitchell, 2001) and the politics of representation (Massey, 1996). 
5.10 We also used our critical sociological perspective to draw attention to the equity aspects of symbolic consumption in this paper. We argued that the consumption of place should be linked to issues of inclusion and exclusion (Kennedy, 1996). For example, leisure is presented as a free and voluntary activity yet it involves struggles over scarce resources and actors are constrained by structural forces such as income (Hall 1994; Shaw and Williams, 1997). Mitchell (2001) argues that landscape is the site of the reconstruction of citizenship, often an exclusionary form of citizenship. We noted that access to natural resources often are linked to political and ethical struggles over access rights, land ownership and national identity (see Wightman, 1995; Mitchell, 2001 for examples).

5.11 As Redclift (1997) suggests, our relationship with nature reveals a great deal about relationships of power and inequality between ourselves. We argued that the sustainable use of water must be thought about in terms of environmental justice. Article Nine of WFD discusses the use of cost recovery to act as an economic driver for sustainable water use, and the WEWS Act says Ministers may consider the social, environmental and economic effects of cost recovery. We were critical of the 'may', which sidesteps the serious social consequences of cost-recovery when implemented without attention to equity issues. We also critiqued the organisation's emphasis on technological fixes for environmental problems which ignore the differing ability to pay for these solutions (Bluden, 1999).

5.12 Our paper drew attention to the relative lack of attention to environmental justice during meetings, arguing that SEPA were not explicitly considering intra-generational justice, one of the fundamental tenets of sustainability (Dragon and Jakobsson, 1997). The notion of inter-generational equity also builds on the notion of social justice, or the 'just redistributive social order' envisaged by Rawls (1971, quoted in Smith, 1999) but extends it to a social contract between generations. Thus current actions should not have a negative effect on the life chances of future generations ${ }^{[7]}$. In the paper, we linked inter-generational equity to the existence value of water, where something is valued just because it exists and the option value, which recognizes the future possibilities of use. These socio- political implications of regulating water quality were a challenge for our participants as they traditionally focused on ensuring water quality rather than considering how the resource was allocated, or who benefited from the pattern of resource use, both now and in the future.

\section{Example Three: Active involvement of consumer-citizens in implementing the WFD}

5.13 Our sociological perspective also informed our critique of SEPA's approach to consumer-citizen involvement in the implementation of the WFD, which was provided via informal feedback given to participants during the final stages of the research. Reflecting on the way that SEPA defined partners and stakeholders during the meetings we attended, we concluded that SEPA tended to define stakeholders as those representing industries discharging to waterways who are regulated under existing and potential pollution legislation and agencies tasked with implementing the WFD (see Sherlock et al, 2004). A stakeholder is generally defined as those who have an interest in a particular decision, either as individuals or representatives of a group. This includes those who influence a decision, or can influence it, as well as those affected by it (Hammati, 2002:2). As highlighted in our reflections on characterisation and water use, all consumer-citizens are stakeholders in the implementation of the WFD, given that human actors are an intrinsic part of the ecosystem, and we all consume water, both literally and symbolically.

5.14 Although SEPA ran an open consultation process on the strategy for the characterisation report, our evidence suggested that SEPA tended to take a narrow, instrumental view of stakeholder involvement, focusing and prioritising the views of those who would be directly involved in the process of regulation, as industries, enforcement agencies or providers of data for use in regulation and planning water resource use (see Sherlock et al., 2004). For example, during WFD meetings, participants talked about defining parameters for key stakeholders, who turned out to be those who hold bio-physical data required for the characterisation report. There were extended discussions about how to screen out 'minor data holders' and interest groups who wished to provide qualitative data considered too 'subjective' and time consuming to be included (see Sherlock et al, 2004). This illustrates that our participants did not see merit in the substantive arguments for consumer-citizen involvement, whereby encouraging multiple perspectives improves understanding and therefore decision making. This approach reinforces the problems with the characterisation report discussed above, namely the failure to develop an interdisciplinary understanding of the causes and consequences of environmental pressures.

5.15 Our evidence also indicated that our participants did not accept there were normative reasons for encouraging consumer-citizen involvement in implementing the WFD. Content analysis of the meeting and interview transcripts highlight how members of the public were rarely mentioned, and consumer-citizens were not considered stakeholders in the characterisation process. Certainly, we did not hear anyone promoting consumer-citizen involvement in order to encourage social learning to enrich both society and individual citizens. So, although Article 14 of the WFD calls for 'active involvement' of interested parties to 
be encouraged by the competent authorities in each member state, the narrow interpretation of stakeholders was likely to exclude consumer-citizens' perspectives from the characterisation process. Thus, the foundation stage for the WFD has been informed by a limited group of data providers and enforcement agencies with extensive quantitative data on pollution and environmental impacts.

5.16 Not only does this narrow approach to defining stakeholders circumscribe understandings of 'sustainable use', it also reinforces the trend for 'participation' to focus on actors representing groups with the most political, economic and social resources in society (Dore and Woodhill, 1999; Pellizzoni, 2001). Our researcher argued that the way in which voices are included or excluded can be linked to the power of the individual or institution to ensure that their construction of reality is seen as more valid and legitimate than others (Fischer, 2000; Pellizzoni, 2001). She argued that the host organisation's current approach is a form of authoritarian technocracy (Smith, 1998) whereby the 'strong state' exerts control over potential hazards, centralizing power and control in the hands of a knowledge elite, which is contrary to the ethos of deliberative democracy at the heart of the WFD. Instead, our researcher advocated for the greater involvement of citizens and consumers, reiterating the importance of civil society in the regulation process.

5.17 Our researcher pointed out that the narrow interpretation of stakeholder might contravene the requirements of the WEWS Act. She noted that the Scottish Executive policy memo states that the host organisation will be required to publish a report demonstrating how they have sought and had regard to the views of a wide variety of interest groups and stakeholders (2002:8; our italics). There is also the impetus of the Aarhus Convention (United Nations, 1998) that requires active involvement of consumer-citizens in environmental decision making. This context provides a rationale for engaging citizens that is imbued with rational-legal authority, making them more compelling for the host organisation. We also pointed out that the implementation of the WFD is subject to the larger debates about empowering localism (O'Riordan and Voisey, 1998). In this way, we used our sociological imagination to stress how a genuinely participatory approach is fundamental for the successful implementation of the WFD.

\section{Reactions}

6.1 Our experience of developing interdisciplinary relationships has been positive. Managers have been receptive to our sociological challenges to their approach to the WFD. More generally, participants were 'awaiting our results with bated breath' (meeting, December, 2002) with 20 individual participants explicitly requesting to be informed of our findings, which indicates an interest in alternative disciplinary perspectives. We believe our collaboration has created a positive orientation to interdisciplinary research within the host organisation and their partner organizations. In the words of one participant 'you've done a good $P R$ job for Sociology' (field notes, December, 2002). Furthermore, experiencing disciplinary interactions during the research process has helped develop our analytical approach to the data. The positive outcomes for both the host organisation and the research team indicate the benefits of engaging in interdisciplinary research on environmental matters.

6.2 With regard to the characterisation report, the act of passing our draft conference paper by the chairperson provided an opportunity for them to reflect on our observations. The critique of a 'sympathetic outsider' (Pawson and Tilley, 1997) provided the impetus for action. Our commentary also strengthened the voices of participants keen to include socio-economic perspectives within the characterisation report. This was raised in eight meetings, with one participant arguing "it seems to me the only solution to the pressures and impacts is economic in one sort of way or another' (Meeting, May, 2002). A major work package on the socio-economics of water use was initiated within SEPA in 2003 that will go some way to counterbalance the focus on ecology and bio-physical science approaches.

6.3 Responding to our paper on the social uses of water, the working group commented that the sociological perspective was unusual but our arguments made intuitive sense. All agreed that the principles raised were central to the WFD and were arguably part of their extended duties. The paper was passed directly to the sponsor department for review and then passed to the internal board overseeing the implementation of WFD. We have since heard that the recommendations have been incorporated into the 2003-2004 corporate work plan, which was described by one key participant as 'a real result' (pers. comm). For example, SEPA's board have commissioned internal research on environmental justice and the distributive effects of WFD cost-benefit analyses have been included in commissioned research on WFD Annex three. Thus, applying the sociological imagination has helped to broaden the working group's understanding and should help them develop an interdisciplinary and holistic approach to sustainable water use under the WFD.

6.4 Feedback on stakeholder involvement was discussed with the appropriate participants. Our discussions allowed the participants to review their rationale for their particular approach to stakeholder involvement and consider how their definition of stakeholders might exclude consumer-citizens. These participants argued that the current stakeholder involvement process was the most extensive ever undertaken by the host 
organisation. While they agreed with our comments, they believe that lack of time and resources (see below) meant they were unable to be as inclusive as they might like. However, the specific

recommendations on stakeholder involvement in the social uses of water paper were adopted as discussed above. The host organisation is now developing broader participatory techniques and held workshops with local communities and stakeholders during 2003 and 2004. This will help deliver the participatory approach that is fundamental to the RBMP process.

6.5 But, despite this positive reception, a number of obstacles remain. Firstly, our field presence exposed us to the day-to-day pressures faced by participants who were being asked to deliver more outcomes with less time available. This was impressed on the research team from the moment we entered the field, and references to pressures created through lack of time were mentioned on 70 occasions. A total of 15 participants were named as being over worked and crisis management due to a lack of staff was mentioned on eight occasions. Lack of staff time is linked to disciplinary commitments as time pressures appeared to be most severe in new areas of responsibility.

6.6 Secondly, a limited pool of resources compounds the problem. In the words of a participant 'If we are tasked with looking after the Scottish environment and sustainability then we have to look at the big picture but it comes down to resources and priorities' (Interview, July, 2002). References in transcripts and interviews highlight the difficulties encountered working within limited budgets. In addition, increased competition for public expenditure and political pressure for cost recovery by public institutions, are likely to increase the resource pressures faced. These echo broader tensions between the agenda of sustainability science and funding shortages in an era of smaller government, as implementing holistic and sustainable approaches can be resource intensive (Warren, 2002; Dore and Woodhill, 1999).

6.7 Thirdly, the challenges of limited time and resources should be placed in the context of rapid organisational growth. For example, references to organisational change were made in 74 of our documents. The restructure in 2001 integrated three quasi-autonomous regional components into one national structure, which is expanding rapidly in response to its increased duties under WFD. It trebled its economic capacity from one to three full time equivalents during 2002, one of whom is tasked with addressing the social, non-market, aspects of sustainable development. To put this in perspective, 21 employees joined between 2000 and 2002 and another 16 existing employees were seconded for WFD duties (SEPA, 2002). Although the organisation is expanding, it remains dominated by the natural sciences rather than developing an interdisciplinary approach to the environment.

6.8 Finally, we found poor communication flows between SEPA's scientific functions to be a major constraint in developing an interdisciplinary approach to the sustainable use of water. Within the scientific community, most individuals seek to increase their status by advancing their expert specialized knowledge (Barnes and Edge, 1982). Some participants drew our attention to resistance to interdisciplinary working within the host organisation, with one participant suggesting that the 'WFD is not interdisciplinary but multiple disciplines and functions working in parallel' (Field Notes June, 2002). We believe that the voices of specialized scientists are being privileged over other generalist voices in the WFD implementation process (Sherlock et al., 2002; 2002a). This impedes the holistic approaches that we suggest are fundamental to implementing sustainable water use in Scotland.

6.9 These are real constraints to developing our recommendations. They explain why there was a strong faction in the organisation, with powerful supporters, who believed that the organisation should 'stick to the $\mathrm{knitting}^{[8]}$ rather than addressing these 'new' areas of responsibility. Our project findings suggest that when faced with a time and resource constrained environment, participants prefer to focus on technical aspects of their work, where their disciplinary expertise ensures that they can achieve their outcomes efficiently. This, together with the strong institutional culture of positivism, militates against developing interdisciplinary, holistic approaches to the environment. These findings support the argument that policy and regulatory choices are restricted to a few 'manageable options' (Gouldson and Murphy, 1998).

6.10 Our analysis suggests that thinking sociologically, that is critically reflecting on current approaches to water regulation, and who benefits from these arrangements, was resisted by our participants due to the lack of time and the way in which these perspectives challenged their own disciplinary traditions. With regard to SEPA's stakeholder partners (see Sherlock et al, 2004) it is possible that taking a sociological perspective would be seen as threatening their interests as producers, by challenging the way that water resources are valued and distributed. However, our evidence suggests that our bureaucratic participants agreed with our sociological critique in principle, but were uncertain how to integrate these new ways of conceptualising water with their traditional approach to water regulation. In this way, when the sociological imagination was resisted, it was due to these participants' 'vested interests' in retaining their status within the organisation, which was earned through completing tasks in a manner in keeping with the institutional culture of using positivist scientific approaches in an efficient and predictable manner. 
6.11 However, our ideas also provided a resource for some participants to challenge the current approach to the WFD within their organisation. Institutional adjustment occurs within policy networks that are constantly coalescing and fissuring (Bessant, 2001; O'Riordan and Voisey, 1998) and participants varied in their ideological and disciplinary preferences. Far from a binary opposition between the 'host organisation' and our researcher, the resistance to the sociological imagination was dependent on the particular participant's perspective. Some participants used the researcher's ideas to highlight alternative discourses in the organisation. Our commentaries (the conference paper, briefing paper and verbal feedback) offered useful breaching points for those participants who were committed to a sustainability perspective rather than a more traditional science perspective. Equally, these discussions were invaluable to us in gaining insight into the institutional culture through the participants' varied reactions to our ideas.

\section{Conclusion}

7.1 This paper illustrates how developing relationships between sociologists and environmental regulators can assist in developing an interdisciplinary, participatory and equitable perspective on sustainable use of water. Our research project, Disciplinary Interactions, concluded that SEPA are finding the new approach to regulating diffuse pollution under the WFD challenging due to the combination of disciplinary commitments and path dependency (Kirk et al., forthcoming, Reeves et al., forthcoming). This paper was stimulated when reflecting on these findings in light of SEPA's request for alternative, sociological, perspectives on their approach to regulation.

7.2 By contributing a new disciplinary perspective, one that focused on the 'social', we sought to broaden SEPA's understanding of water use. We demonstrated that the environmental perspective must be combined with a sociological perspective, as the human - environment relationship is an 'intensely political process' (Warren, 2002: 16). We argued that taking a purely bio-physical approach to the characterisation report will not deliver sustainable use of water, as the causes and consequences of environmental problems are social issues (Giddens, 2001). The narrow approach to the characterisation had consequences for their approach to water use, which focuses on water as a factor of production rather than part of a landscape of consumption. We also drew attention to notions of equity, which had been largely ignored by the host organisation. We challenged the narrow interpretation of stakeholder involvement and we highlighted how the exclusionary approach contradicted the ethos of sustainability.

7.3 By focussing on the technical bio-physical aspects of the WFD, the host organisation had temporarily side stepped these complex issues. Although participants know it could not be ignored forever, they were at a loss to know how to incorporate this subjective and highly politicised issue into their institutional processes, which are shaped by a dominant culture of value free 'sound science'. Our influence was timely, as the organisation is responsible for developing the programmes of measures that will protect Scotland's water resources for the foreseeable future. Our contributions helped to develop an approach to WFD that extends beyond the usual 'technological fix' (Newby, 1997). In this way, we believe the introduction of a different disciplinary perspective contributed to the organisation's quest to achieve the WFD goal of sustainable water use.

7.4 Our experiences must be considered in light of constraints to developing interdisciplinary relationships. Our perspectives were mobilized by participants who embrace these new challenges. Our arguments strengthened the position of those who wanted to tackle pollution by engaging with educated and informed consumer-citizens, rather than legislate those who continue to pollute. However, our arguments were resisted by those who take a narrower view of 'core business'. These participants perceive the constraints of time, resources and skills deficit as reasons to resist interdisciplinary approaches for sustainable outcomes. It is these barriers that will have to be addressed when developing relationships between sociology and science.

7.5 The paper is also a response to the call for more sociologists to engage in the contested debates surrounding sustainability. Newby (1997) argues that the contribution of sociologists to the environmental debate has been 'disappointing', despite the centrality of environmental concerns to the Western political agenda (Elliott, 1998). Our experience has highlighted how sociologists are well placed to contribute to the material protection of the environment through analysis of the subjective and symbolic aspects of the environment. We challenge other sociologists to develop relationships between 'sociology, science and sustainability' as we agree that 'sociological techniques and insights are an integral part of finding solutions to our pressing environmental problems' (Newby, 1997: 479).

\section{Notes}

${ }^{1}$ Our Disciplinary Interactions research questions were: How much does previous policy/legislation shape the outcome of new policies and legislation?; Which science is included in the decision-making process 
and are any voices excluded?; Does the background of the decision-makers affect the policy/legislation outcome? And what are the bureaucratic constraints on policy-making? However, the paper focuses on how the field researcher's own discipline, and therefore her sociological imagination, could be use to inform the way that SEPA think about regulating sustainable water use.

${ }^{2}$ Citizenship is a contested concept (Butcher and Mullard, 1993) which refers to the relationship between the individual and the state. We do not have space to enter the debates over mechanism of awarding citizenship, different types of citizenship, inclusion and exclusion through formal citizenship processes in this paper.

3 However, sustainable development is a form of discourse, which both shapes and is shaped by competing ideologies, thus it can be claimed by both conservative and liberal advocates of social change (Smith, 1999; Warren, 2002). For a commentary on this debate, see Doherty (1996) or Yearly (1991).

${ }^{4}$ Intra-generational use refers to equity issues in current society but inter-generational equity refers to distribution issues between generations. These issues are discussed further through the paper.

${ }^{5}$ Engineering, Geography, Oceanography, Physics, Chemistry, Environmental Science, Biology, Zoology, Geology, Agriculture, Environmental Management.

${ }^{6}$ Surprisingly, not the economist!

7 The exact nature of this contract and the extent of future obligation remain contested (Kakva and Warren, 1999).

8 These are the words of a participant (Interview, November, 2002).

\section{Acknowledgements}

The authors would like to acknowledge the support of the Scottish Environment Protection Agency and the ESRC which provided research funding for the project. The views expressed are those of the authors alone.

\section{References}

AITCHISON, C., MACLEOD, N. AND SHAW, S. (2000) Leisure and Tourism Landscapes: Social and Cultural Geographies. London: Routledge

ARTHUR,B.W. (1994) Increasing Returns and Path Dependence in the Economy. Ann Arbor: University of Michigan Press

BABER W F (2004) Ecology and democratic governance: toward a deliberative model of environmental politics in The Social Science Journal 41 pp 331 - 346

BARNES, B. AND EDGE, D. (1982) Science in Context: Readings in the Sociology of Science. Milton Keynes: Oxford University Press

BAUMAN, Z. (1990) Thinking Sociologically, Oxford: Basil Blackwell

BECK, U. (1992) Risk Society: Towards a New Modernity. London: Sage Books

BEIRLE TAND KONISKY D (2001) What are we gaining from stakeholder involvement? Observations from Environmental planning in the Great Lakes in Environment and Planning C, 19, pp 483 - 500

BESSANT, J. (2001) 'A sociology of policy makings' in TASA Conference Proceedings, [CD-ROM], conference held $13^{\text {th }}-15^{\text {th }}$ December, 2001, Sydney (eds. Browne T, Edwards K, Watson $V$ and Van Krieken R)

BECKER, M. AND FEHR, G. (2002) 'The Dashboard of Sustainability for Catchments: Aggregating Catchment modelling with Sustainable Planning - an interdisciplinary approach' in the IWA Watershed and River Basin Management Conference Proceedings, [CD-ROM] conference held $11^{\text {th }}-13^{\text {th }}$ September, 2002, Edinburgh

BUTCHER, H. AND MULLARD, M. (1993) 'Community Policy, Citizenship and Democracy' in Butcher, H. and Glen, A. (editors) Community and Public Policy London: Pluto Press 
BLUDEN, J. (1999) Freshwater: A natural resource issue for the twenty first century? in Smith, M. J. (editor) Thinking through the Environment. London: Routledge.

CHALMERS, T. (1982) What is this thing called Science? Brisbane, Australia: University of Queensland Press.

COUNCIL OF THE EUROPEAN UNION (2000) Water Framework Directive 2000/60/EC;

<http://europa.eu.int/> [accessed $17^{\text {th }}$ June, 2002 at 14.48]

DOHERTY, B. (1996) Democracy and Green Political Thought: Sustainability, rights and community. London: Routledge

DORE, J. AND WOODHILL, J. (1999) Sustainable Regional Development. Canberra: Greening: Australia.

DRAGON, D. K. AND JAKOBSSON, K. M. (1997) 'Conclusions: Future Horizons for Global Environmental Policy' in Dragon, D. K. and Jakobsson, K. M. (editors)

Sustainable and Global Environmental Policy: New Perspectives, Cheltenham: Edward Elgar Publications.

EDWARDS, R. W. (1997) 'Introduction' in Booth, P. J. and Howell, D. L. (editors) Freshwater Quality:

Defining the Indefinable. Edinburgh: the Stationary Office,

ELLIOTT, R. (1998) 'Introduction' in Elliott, R. (editor) Environmental Ethics. Oxford: OUP

ENVIRONMENT PROTECTION AGENCY (2003) Environmental Justice

http://www.epa.gov/compliance/environmentaljustice/ [accessed 17 $7^{\text {th }}$ March, 2003])

FISCHER,F. (2000) Citizens, Experts and the Environment: the Politics of Local Knowledge (Duke University Press, Durham, NC)

FOUCAULT, M. (1991) 'Govermentality' in Burchell, G., Gordon, C. and Miller, P. (editors) The Foucault Effect: Studies in Governmental Rationality. Hemel Hempstead: Harvester Wheatsheaf.

GIDDENS, A. (1991) Modernity and Self-Identity. London: Polity Press

GIDDENS, A. (2001) Sociology [4 ${ }^{\text {th }}$ Edition]. Oxford: Blackwells.

GOLDBLATT, D. (1999) 'Risk society and the environment' in Smith, M. J. Thinking through the Environment. London: Routledge.

GOULDSON, A. AND MURPHY, J. (1998) Regulatory Realities: the Implementation and Impact of Industrial Environmental Regulation. London: Earthscan Publications.

HALL, C. M. (1994) Tourism and Politics: Policy, Power and Place. Chichester, UK: John Wiley and Sons. HAMMATI M (2002) Multi-Stakeholder Processes For Governance and Sustainability, London: Earthscan Publications

HAMILTON, C. (1996) 'Generational Justice: The marriage of sustainability and social equity' in Australian Journal of Environmental Management 3 (3), pp 163-173.

HARRINGTON, B. (2002) 'Obtrusiveness as a Strategy in Ethnographic Research' in Qualitative Sociology Vol. 25 (1) pp 49 - 62

HASSARD, J. AND KELEMEN, M. (2002) 'Production and Consumption in Organisational Knowledge: the case of the paradigm Debate' in Organization Vol. 9 (2) pp 331 - 355.

HOBSBAWN, E. AND RANGER, T. (1987) The Invention of Tradition, Cambridge: Cambridge University Press.

JASANOFF, S. (1999) 'Cross National Differences in Policy Implementation' in Hutter, B.M. (editor) A Reader in Environmental Law. Oxford: Oxford University Press.

KAKVA, G. S. AND WARREN, V. (1999) 'Can future generations be represented?' in Smith M. J. (editor) Thinking through the Environment. London: Routledge 
KATES, R.W, CLARK WC, CORELL R, HALL JM, JAEGER CC, LOWE I, MCCARTHY JJ,

SCHELLNHUBER HJ, BOLIN B, DICKSON NM, FAUCHEUXS, GALLOPIN GC, GRÜBLER A, HUNTLEY B, JÄGER J, JODHA NS, KASPERSON RE, MABOGUNJE A, MATSON P, MOONEY H, MOORE III B, O'RIORDAN T, SVEDIN U (2001) 'Sustainability Science' in Science Magazine Vol. 292 Pp 641 - 642

KENNEDY, P. (1996) 'Capitalist Enterprise as moral or political crusade: Opportunities, Constraints and Contradictions', O'Connor J and Wynne D (editors) in From the Margins to the Centre. London: Arena.

KIRK E.A, REEVES A.D AND BLACKSTOCK K.L. (forthcoming) 'Disciplinary Interactions: Path Dependency and Environmental Regulation' to be submitted to Environment and Planning $C$

KIRK, E.A. AND REEVES, A.D. (2002) 'Disciplinary Interactions: Ontological Commitments and Environmental Standard Setting' in Current Legal Issues (5) pp 557 - 573.

KIRK E.A., SHERLOCK K.L. AND REEVES A.D. (2004) SUDS Law: Non-state actors and the haphazard route to the implementation of international obligations in Journal of Non-State Actors and International Law, 4, 87-109.

KRAMER, L. (2000) 'Water Protection' in European Commission Environmental Law Pp 183 - 204. London: Sweet and Maxwell.

LANDESMAN, C. (1997) an Introduction to Epistemology, Oxford: Oxford University Press.

LINEHAU, J. R., AND GROSS, M. (1998) 'Back to the Future, back to basics: the social ecology of landscapes and the future of landscape planning' in Landscape and Urban Planning 42, Pp 207 - 223.

LUBCHENCO, J. (1998) 'Entering the Century of the Environment: A New Social Contract for Science' in Science Magazine Vol. 279 in Pp 491 - 497.

MCCRONE, D, MORRIS, A. AND KIELY, R. (1995) Scotland - The Brand: the Making of Scottish Heritage . Edinburgh: Edinburgh University Press

MASSEY, D. (1996) 'Power-Geometry and a progressive sense of place' Pp 59 - 69, in Bird. T., Curtis, B., Putnam, T., Robertson, G. and Tickner, L. (editors) Mapping the Futures: Global Cultures, Local Change , London: Routledge Books.

MILLER, G. (1997) 'Introduction: Context and Method in Qualitative Research' in Miller, G. and Dingwell, R. (editors) Context and Method in Qualitative Research. London: Sage Publications.

MILLS C. W. (1959) The Sociological Imagination, New York: Oxford University Press

MITCHELL, D. (2001) 'The Lure of the Local: Landscape Studies at the end of a troubled Century' in Progress in Human Geography 25(2) pp 269 - 281.

MURPHY, R. (2002) 'The internalization of autonomous Nature into Society' in Sociological Review 50 (3) August, pp 313 - 333.

NEWBY, H. (1997) 'One World Two cultures: Sociology and the Environment' in Owen, L. and Unwin, T. (editors) Environmental Management: Readings and Case Studies. Blackwell, Oxford...

NEWSON, H. (1996) 'Land, Water and Development: Key Themes Driving International Policy on Catchment Management' in Cresser, M. and Pugh, K. (editors) Multiple Land Use and Catchment Management. Aberdeen: Macaulay Land Use Research Institute.

NEWTON, T. (1999) 'Power, Subjectivity, British Industry and Organizational Sociology: the relevance of the work of Norbert Elias' in Sociology 33 (2) pp 411 - 440.

O'CONNOR, P. (2000) 'Your Place, My Place: Heritage Studies and the Micro/macro Notions of Place', Paper presented at Habitus: A sense of place , [CD-ROM] Conference held 5-9th September, 2000, Perth, Australia

O'CONNOR, J. AND WYNNE, D. (1996) 'Introduction', in O'Connor, J. and Wynne, D. (editors) From the Margins to the Centre: Cultural Production and Consumption in the Post-industrial City. Aldershot, UK: Arena,

O'NEILL J (2001) Representing People, Representing Nature, Representing the World in Environment and Planning C, 19, pp $483-500$ 
O'RIORDAN, T. AND VOISEY, H. (1998) 'The political economy of the Sustainability transition' in O'Riordan, T. and Voisey, H. (editors) Agenda 21: the Transition to Sustainability in Europe. London: Earthscan.

OECD (2001) Citizens as partners: Information Consultation and public participation in policy making, OECD, Paris, France

OWEN, L. AND UNWIN, T. (1997) 'Introduction' in Owen, L. and Unwin, T. (editors) Environmental Management: Readings and Case Studies. Blackwell, Oxford,)

PAWSON, R. AND TILLEY, N. (1997) Realistic Evaluation. London: Sage Publications

PELLIZZONI L (2001) The myth of best argument: power, deliberation and reason in British Journal of Sociology 52 (1) pp 59 - 86

REKOLAINEN, S, KAMARI, J AND HILTUNEN, M (2004) A conceptual framework for identifying the need and role of models in the implementation of the Water Framework Directive, International Journal of River Basin Management 4: 347-352.

REDCLIFT, M. (1997) 'Sustainable Development: Needs, Values, Rights' in OWEN, L. AND UNWIN, T. (editors) Environmental Management: Readings and Case Studies. Blackwell, Oxford.

REEVES A.D., KIRK E.K, AND BLACKSTOCK K.L. (forthcoming) Diffuse pollution:

Barriers to the development of holistic managements measures at institutional level in Scotland to be submitted to Total Science of the Environment

ROSS, A (2000) 'Introduction' in Environment and Regulation, Hume Papers on Public

Policy: 8 (2); Edinburgh: Edinburgh University Press, pp 1 - 5.

SCOTTISH ENVIRONMENT PROTECTION AGENCY (2002) Water Framework Directive Implementation Plan 2002/03; Stirling: SEPA Corporate Office (internal document).

SCOTTISH EXECUTIVE (2002) Water Environment and Water Services Bill Policy Memo ; Edinburgh: Scottish Executive.

SCOTTISH EXECUTIVE ENVIRONMENT GROUP (2002a) The Future for Scotland's Waters - Proposals for Legislation; Edinburgh: Scottish Executive.

SCOTTISH EXECUTIVE (2001) Rivers, Lochs, Coasts: The Future for Scottish Waters; Edinburgh: Scottish Executive.

SCOTTISH EXECUTIVE (2000) Creating our Future... Minding our Past: Scotland's National Cultural Strategy, <http://www.scotland.gov.uk/nationalculturalstrategy/docs/cult-00.asp >. [accessed $15^{\text {th }}$ November, 2002)

SHAFFIR, W. AND STEBBINS, R. (1991) 'Introduction', Shaffir, W. and Stebbins, R. (editors) in Experiencing Fieldwork: An inside View of Qualitative Research, London: Sage Publications.

SHAW, G. AND WILLIAMS, A. (1997) Critical Issues in Tourism: A Geographical Perspective . Oxford: Blackwell Publishers.

SHERLOCK, K.L., KIRK, E.A. AND REEVES, A.D (2004) Just the usual suspects? Partnerships and environmental regulation in Environment and Planning C: Government and Policy, 22, 651-666.

SHERLOCK, K., REEVES, A., KIRK. E. A. AND SINCLAIR, C. (2002) Institutional challenges faced when developing a River Basin District Plan: a Scottish Case Study; a poster paper presented at $9^{\text {th }}$ International Specialized Conference on Watershed \& River Basin Management, Edinburgh, 11-13 ${ }^{\text {th }}$ September, 2002.

SHERLOCK, K., REEVES, A. AND KIRK, E. A. (2002a) Institutional challenges of implementing the Water Framework Directive: a Scottish Case Study; a conference paper presented at the Science for Water and Policy Conference, Norwich, $2^{\text {nd }}-4^{\text {th }}$ September 2002.

SHRIVE, E. (1994) 'Sustaining Development in Environmental Sociology' in Redclift, M. and Benton, T. (editors) Social Theory and the Global Environment . London: Routledge.

SILVERMAN, D. (2000) Doing Qualitative Research: A Practical Handbook . London: 
Sage Publications.

SLOCUM, R (2004) Consumer citizens and the cities for climate protection campaign, in Environment and Planning A, 36 (5) 763 - 782

SMITH, M. J. (1999) 'Intergenerational Justice' in Smith, M. J. (editor) Thinking through the Environment. London: Routledge.

SMITH M. J. (1999a) 'Voyage into the Unknown' in Smith, M. J. Thinking through the Environment. London: Routledge.

SMITH, M. J. (1998) Ecologism: Towards Ecological Citizenship, Milton Keynes; OUP

STIRLING A (in press) Analysis, participation and power: justification and closure in participatory multicriteria analysis in press, Land Use Policy

TRESS B, TRESS G AND FRY G (2005) Integrative studies on rural landscapes: policy expectations and research practice in Landscape and Urban Planning 70 (1-2): 177-191

TURNER, B. AND ROJEK, C. (2001) Society and Culture: Principles of Scarcity and Solidarity ; London: Sage Publications

UNITED NATIONS ENVIRONMENTAL COMMITTEE (1998) Convention on access to information, public participation in decision making and justice in environmental matters,

$<$ http://www.unece.org/env/pp/documents/cep43e.pdf> [accessed $18^{\text {th }}$ March, 2003]

VAN DEN HOVE, S (2000) Participatory approaches to environmental policy making: the European Commission Climate Policy Process as a case study, Ecological Economics 33 pp 457 - 472.

VICORY, A., STANISKIS. J., HEATH, J., AND DAVENPORT, J. (2002) 'Building Capacity of the Baltic States to meet EU Water Framework Directive through Watershed Demonstration Projects' in the IWA Watershed and River Basin Management Conference Proceedings; [CD-ROM] conference held $11^{\text {th }}-13^{\text {th }}$ September, 2002, Edinburgh.

WAKEFORD, T. AND WALTERS, M. (1995) 'Introduction' in Wakefield, T. and Waters, M. (editors) Science for the Earth: Can Science make the World a better place? Chichester: John Wiley and Sons.

WALKER, B, HOLLING, C S, CARPENTER, R AND KINZIG, A (2004) Resilience, adaptability and transformability in social-ecological system in Ecology and Society 9(2): 5. [online] URL:http://www.ecologyandsociety.org/vol9/iss2/art5/.

WARREN,C. (2002) Managing Scotland's Environment. Edinburgh University Press, Edinburgh.

WEBLER T, TULER S, AND KRUEGER R (2001) What is a good public participation process? Five perspectives from the public in Environmental Management 27 (3) pp 435 - 450

WIGHTMAN, A. (1996) Who Owns Scotland? Edinburgh: Canongate Press.

WORLD COMMISSION ON ENVIRONMENT AND DEVELOPMENT (1987) Our Common Future. Oxford: Oxford University Press.

YEARLY, S. (1991) The green case: a sociology of environmental issues, arguments and policy . London: Routledge. 